\title{
Broadband Records of Earthquakes in Deep Gold Mines and a Comparison with Results from SAFOD, California
}

\author{
by A. McGarr, M. Boettcher, J. B. Fletcher, R. Sell, M. J. S. Johnston, \\ R. Durrheim, S. Spottiswoode, and A. Milev
}

\begin{abstract}
For one week during September 2007, we deployed a temporary network of field recorders and accelerometers at four sites within two deep, seismically active mines. The ground-motion data, recorded at $200 \mathrm{samples} / \mathrm{sec}$, are well suited to determining source and ground-motion parameters for the mining-induced earthquakes within and adjacent to our network. Four earthquakes with magnitudes close to 2 were recorded with high signal/noise at all four sites. Analysis of seismic moments and peak velocities, in conjunction with the results of laboratory stick-slip friction experiments, were used to estimate source processes that are key to understanding source physics and to assessing underground seismic hazard. The maximum displacements on the rupture surfaces can be estimated from the parameter $R \underline{v}$, where $\underline{v}$ is the peak ground velocity at a given recording site, and $R$ is the hypocentral distance. For each earthquake, the maximum slip and seismic moment can be combined with results from laboratory friction experiments to estimate the maximum slip rate within the rupture zone. Analysis of the four $M 2$ earthquakes recorded during our deployment and one of special interest recorded by the in-mine seismic network in 2004 revealed maximum slips ranging from 4 to $27 \mathrm{~mm}$ and maximum slip rates from 1.1 to $6.3 \mathrm{~m} / \mathrm{sec}$. Applying the same analyses to an $M 2.1$ earthquake within a cluster of repeating earthquakes near the San Andreas Fault Observatory at Depth site, California, yielded similar results for maximum slip and slip rate, $14 \mathrm{~mm}$ and $4.0 \mathrm{~m} / \mathrm{sec}$.
\end{abstract}

\section{Introduction}

TauTona Gold Mine, located about $80 \mathrm{~km}$ west of Johannesburg, South Africa, is currently the deepest in the world and also one of the most seismically active. Adjacent to TauTona, nearly as deep, and also seismically active, is Mponeng Gold Mine. The mining-induced tremors within these two mines, with magnitudes occasionally exceeding 4 , pose a substantial hazard to the deep mining operations, but they also provide an opportunity to study moderately large earthquakes at close hand because of the access provided by the mine infrastructure. Both of these mines, as well as the other gold mines in this district, have extensive inmine seismic networks that are operated by Integrated Seismic Systems International (e.g., Mendecki, 1997). These inmine networks provide precise hypocentral locations and various source parameters for the mining-induced earthquakes at low magnitude thresholds.

From 18 to 25 September 2007, we deployed four field stations, on loan from IRIS/PASSCAL, at the locations shown in Figure 1. In TauTona, stations T066 and T120 were sited near the vertical shafts that provide access to the under- ground workings, and T118 was located within the Natural Earthquake Laboratory, South African Mines (NELSAM) experimental area (Reches et al., 2006), not far from the deepest part of the mine. M116 was located at a site near the south edge of Mponeng Mine, where seismic experiments are being performed by a Japanese-South African group (Ogasawara et al., 2002). As seen in the inset of Figure 1, a cross section looking westward, three of the sites are at depths near $3600 \mathrm{~m}$ and the fourth, T066, is at a depth of about $2000 \mathrm{~m}$.

Each station (Fig. 2) was installed within a small alcove and the accelerometers were glued to the base surfaces. The field recorders had sufficient memory to record continuously at 200 samples/sec for the duration of this experiment. Although our deployment was only for a week, the level of seismicity in these deep mines is sufficiently high that many earthquakes were recorded with excellent signal/noise.

In this report, we first present some of the groundmotion data from nearby mining-induced earthquakes and then use these data to demonstrate techniques for estimating 


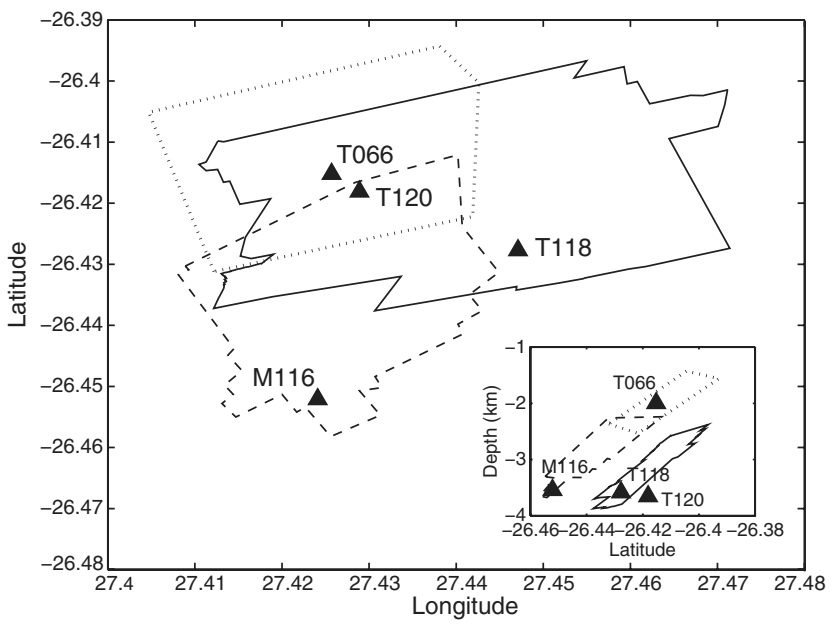

Figure 1. Map and cross-section view looking west (inset) of broadband network. In TauTona gold is extracted from two reefs. The shallower is the Ventersdorp Contact Reef (VCR) indicated by the dotted line, and the deeper is the Carbon Leader Reef (CLR), shown as the solid line in map view. In Mponeng all of the mining to date is from the VCR shown as a dashed line.

the maximum slip and maximum slip rate within the rupture zone of an earthquake. Additionally, to demonstrate that this approach is useful in other settings, we apply the same analysis to a well-studied earthquake of $M 2.1$ within a cluster of repeating earthquakes near the San Andreas Fault Observatory at Depth (SAFOD) site, California, to argue that, in terms of seismic ground motion, hypocentral depth, and source characteristics, the mining-induced earthquakes of this study are similar to the repeater near SAFOD.

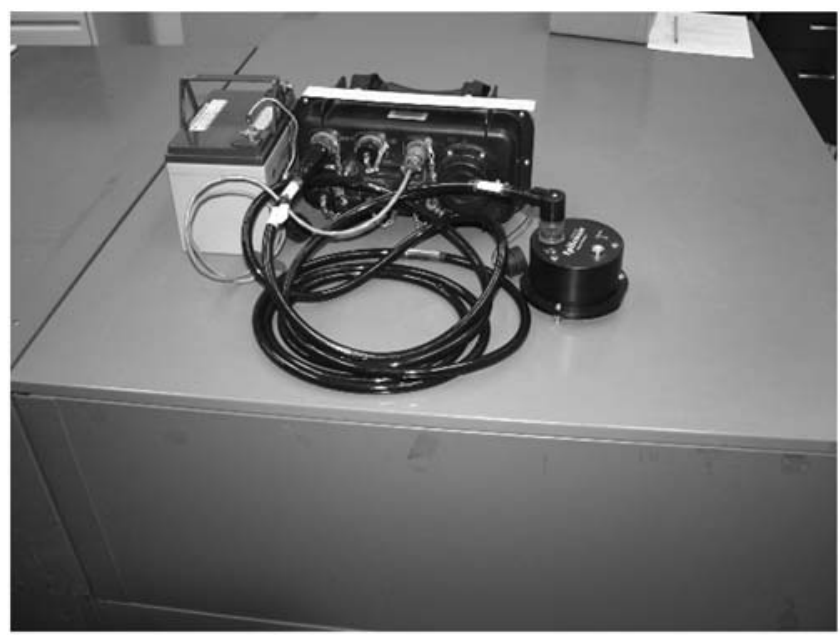

Figure 2. The IRIS/PASSCAL broadband stations used in this project consisted of an Episensor accelerometer and an RT-130 recorder, powered by a 12 volt battery. (Any use of trade names is for descriptive purposes only and does not imply endorsement by the U.S. government.) These units were housed in steel security boxes bolted to the floors in small alcoves.

\section{IRIS/PASSCAL Seismic Data}

During our experiment, six nearby earthquakes, with magnitudes of approximately 2, were recorded. Figure 3 shows a map of their locations, our four station positions, and many faults, one of which is the Pretorius fault zone, which intersects the Mponeng and TauTona mines including the NELSAM site (T118). Events 1 and 2, located to the west of our network (Fig. 3), occurred on 17 September 2007 when only two of our stations had been installed, and so we have left them out of the following analysis and, instead, have focused on events 3-6, which were recorded by all four stations of the network.

Event 3, $M$ 2.4, was located $1.65 \mathrm{~km}$ northeast of T118 (Fig. 3). The ground motion at this station is shown in Figure 4 where we see three components of ground acceleration, velocity, and displacement, all corrected for attenuation using $Q=200$ (Churcher, 1990; Hemp and Goldbach, 1993; Spottiswoode, 1993). Although our use of a frequencyindependent $Q$ may not be the best possible way to take attenuation into account, we found that our correction using $Q=200$ is effective for removing the component of distance dependence that is not associated with geometrical spreading $(1 / R)$. Even after two integrations, from acceleration to velocity and then to displacement, the signal/noise is quite high. Indeed, in addition to the $P$ - and $S$-wave pulses, the near-field contributions to the waveforms are quite evident, especially on the radial component of displacement (top trace, Fig. 4) where we see a ramp between the $P$ - and $S$ wave pulses. Because the hypocenter is $200 \mathrm{~m}$ higher than station T118, the ray path is inclined slightly downward and so the $P$-wave pulse (radially outward), mostly seen on the radial trace, appears as a small downward deflection on the

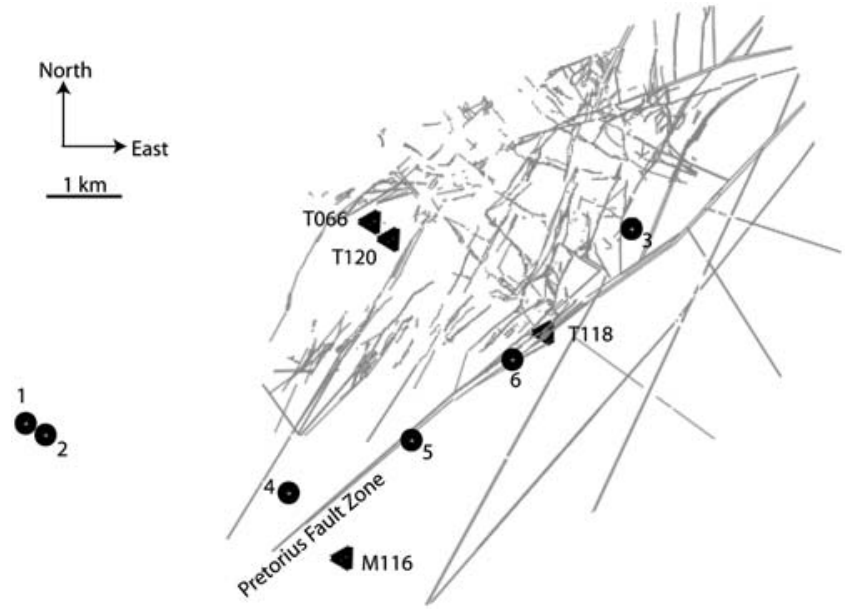

Figure 3. Map view of the temporary stations and six earthquakes with magnitudes of approximately 2 recorded during this deployment. Also shown are some of the faults that intersect the mine workings, including the Pretorius fault. The depths for events 3 to 6 , which were recorded at all four sites, are 3386, 3050, 3028, and $2458 \mathrm{~m}$, respectively. 

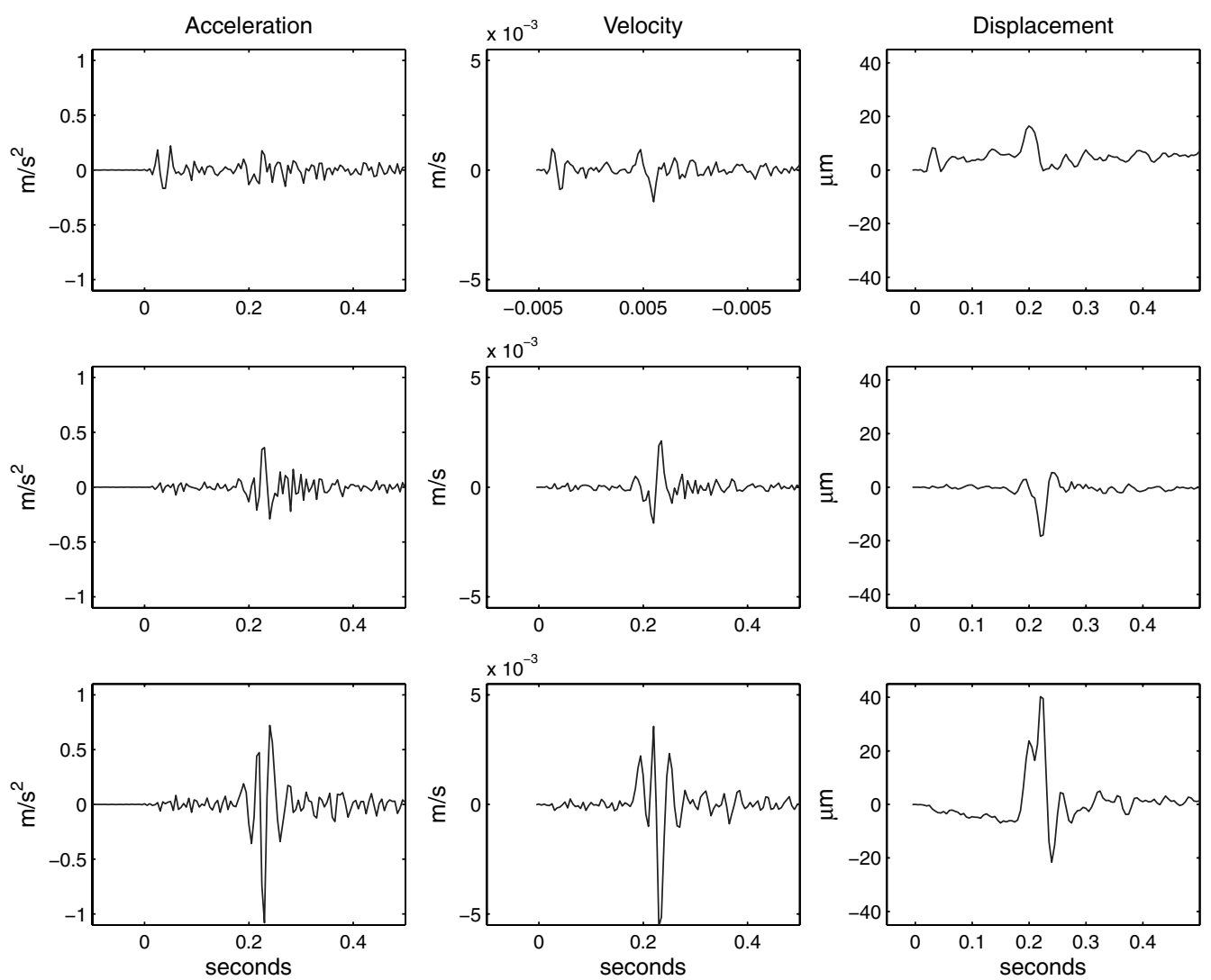

Figure 4. Ground motion for event 3, $M$ 2.4, recorded at station T118 (Fig. 3). From top to bottom, the components are radial, transverse, and vertical. Radial and transverse entail rotations about the vertical axis (i.e., they are horizontal components).

vertical trace. Note that the ramp between the $P$ and $S$ pulses is quite clear on the vertical trace as well.

These clean waveforms allow complete moment tensor solutions to be determined as described by M. Boettcher et al. (unpublished manuscript, 2009; see also, McGarr, 1992a,b). The waveforms at all four stations of the broadband network show similar simplicity and high signal/noise owing to the largely uniform velocity structure within the quartzitic strata and minimal site effects at depth.

In this report, we emphasize the ground velocities and a corresponding ground-motion parameter $R \underline{v}$, where $R$ is the hypocentral distance, and $\underline{v}$ is the peak velocity of the $S$ wave pulse from the vectorially summed traces. We see in Figure 4 that the highest velocity is due to the vertical component of the $S$ wave with lower peak amplitudes on the other two components. For this example (Fig. 4 ), $R$ is $1650 \mathrm{~m}$, and $\underline{v}$ was measured as $5.8 \mathrm{~mm} / \mathrm{sec}$ yielding $R \underline{v}=9.6 \mathrm{~m}^{2} / \mathrm{sec}$.

\section{Event 12/12/2004}

In addition to earthquakes recorded during our IRIS/ PASSCAL deployment, we also analyzed an earthquake of M 2.2 that occurred in December 2004, designated event $12 / 12 / 2004$. Its hypocenter was located close to where the Pretorius fault zone intersects the NELSAM study area at T118 (Fig. 3). This earthquake is of special interest because it was associated with rupture whose slip within the Pretorius fault zone was measured by Reches et al. (2006). Because this earthquake predated our temporary network, our analysis is based on ground motion recorded by the in-mine network (Mendecki, 1997), as will be described.

Part of our motivation for our September 2007 broadband field campaign was the need to resolve some questions concerning the in-mine network including component polarity, orientation, and system response. The method for doing this was to determine moment tensors for the four $M 2$ earthquakes recorded during our deployment and then to use these results to calculate synthetic seismograms at in-mine network sites of interest for comparison with the ground motion actually recorded at the same borehole sites (M. Boettcher et al., unpublished manuscript, 2009). The in-mine network ground motions used to analyze event 12/12/2004 were checked and corrected as needed using this procedure.

\section{Maximum Slip}

Slip models developed for earthquake rupture zones show distributions of slip that are inhomogeneous with patches of high slip separated by zones that often have little or no slip (e.g., Wald and Heaton, 1994). McGarr (1991) developed a relationship between the peak velocity pulse of the $S$ wave and the maximum slip, $D_{\max }$, within the rupture zone 


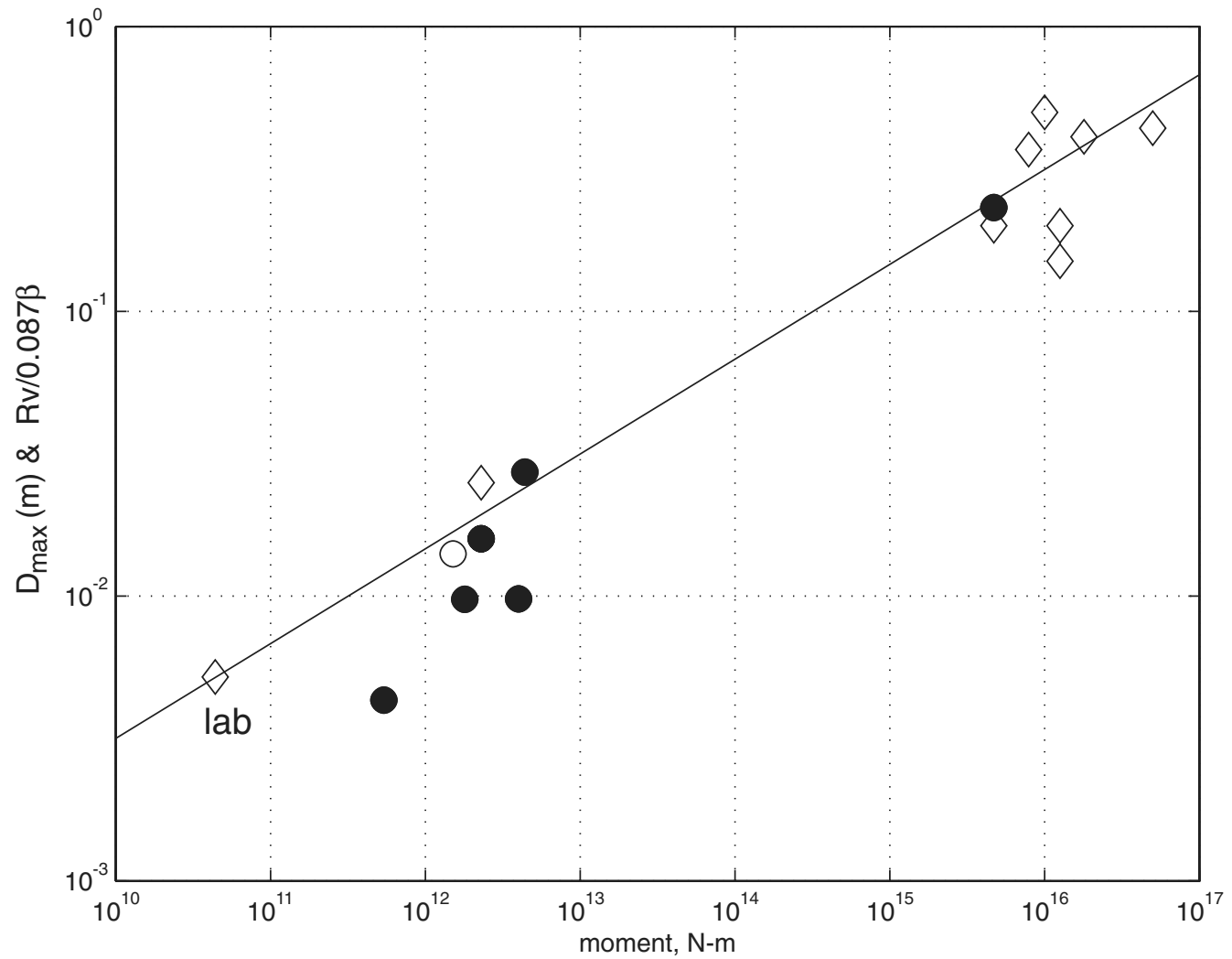

Figure 5. $\quad D_{\max }$ (diamonds) and $R \underline{v} / 0.087 \beta$ (filled circles) as functions of seismic moment for the earthquakes listed in Table 1. The unfilled circle represents $R \underline{v} / 0.087 \beta$ for event 0310201125 . The diamond near $M_{0}=10^{12} \mathrm{~N} \mathrm{~m}$ and the solid circle directly below it denote the $D_{\max }$ and $R \underline{v} / 0.087 \beta$, respectively, for event $12 / 12 / 2004$. The closely situated circle and diamond in the upper right-hand portion of the graph represent the $M 4.4$ event 1040939 (Table 1). The solid line is $D_{\max }=10^{-5.83} M_{0}^{1 / 3}$, the regression fit to a much broader set of maximum slip data (McGarr and Fletcher, 2003); any point along this line represents an earthquake for which the maximum slip rate is $5.2 \mathrm{~m} / \mathrm{sec}$, including adjusted lab event 9 plotted as the diamond at the lower left of the figure.

of an earthquake $R \underline{v}=0.124 \beta D_{\max }$, where $\beta$ is the shear wave speed. For several reasons, as will be explained, we decided to update this relationship. To do this, we start with equation 3 of McGarr (1991), which gives the far-field $S$-wave ground velocity $v(t)$ from a double-couple source

$$
R v(t)=\frac{R_{\theta \phi}}{4 \pi \rho \beta^{3}} \ddot{M}_{0}(t-R / \beta),
$$

where $\rho$ is density, $R_{\theta \phi}$ is the radiation pattern, and $M_{0}(t)$ is the time-dependent seismic moment of the high-slip asperity (e.g., Aki and Richards, 1980, equation 4.32). For an asperity of radius $r$ the rupture is assumed to begin at the periphery and spread around and then inward (Das and Kostrov, 1983) so that $r$ remains approximately constant while the average slip increases from zero to its final value $D_{\max }$ with rise time $T$. Thus, to a good approximation,

$$
\dot{M}_{0}(t)=G \pi r^{2} \dot{D}(t)
$$

where $G$ is the modulus of rigidity and $\dot{D}(t)$ is the slip rate averaged over the asperity. Whereas McGarr (1991) represented the slip rate as a function of form $1-\cos \left(\frac{2 \pi t}{T}\right)$, we have departed from that analysis by using an isosceles triangle of base $T$ and height $\dot{D}_{\text {max }}$, the maximum slip rate, for this purpose. One of the reasons for adopting this triangle representation is that, in contrast to the previous slip-rate function, it yields the expected Brune (1970) spectrum for the far-field $S$ wave (e.g, Hanks and McGuire, 1981). Moreover, isosceles triangles are commonly used to represent slip rates within subfaults that comprise slip models developed for earthquakes (e.g., Wald and Heaton, 1994). Thus, there is considerable precedence for using this triangle representation of slip rate.

We can relate $T$ to the radius of the asperity using (Brune, 1970, 1971)

$$
r=\frac{2.34 \beta T}{2 \pi}
$$

With the triangle representation of slip rate, the maximum amplitude of $\ddot{D}(t)$ is $\ddot{D}_{\max }=\frac{4 D_{\max }}{T^{2}}$, which can be combined with equations (1), (2), and (3) to obtain

$$
R \underline{v}=\frac{R_{\theta \phi}}{4 \pi \rho \beta^{3}} G \pi r^{2} \ddot{D}(t)_{\max }=R_{\theta \phi}\left(\frac{2.34}{2 \pi}\right)^{2} \beta D_{\max }
$$




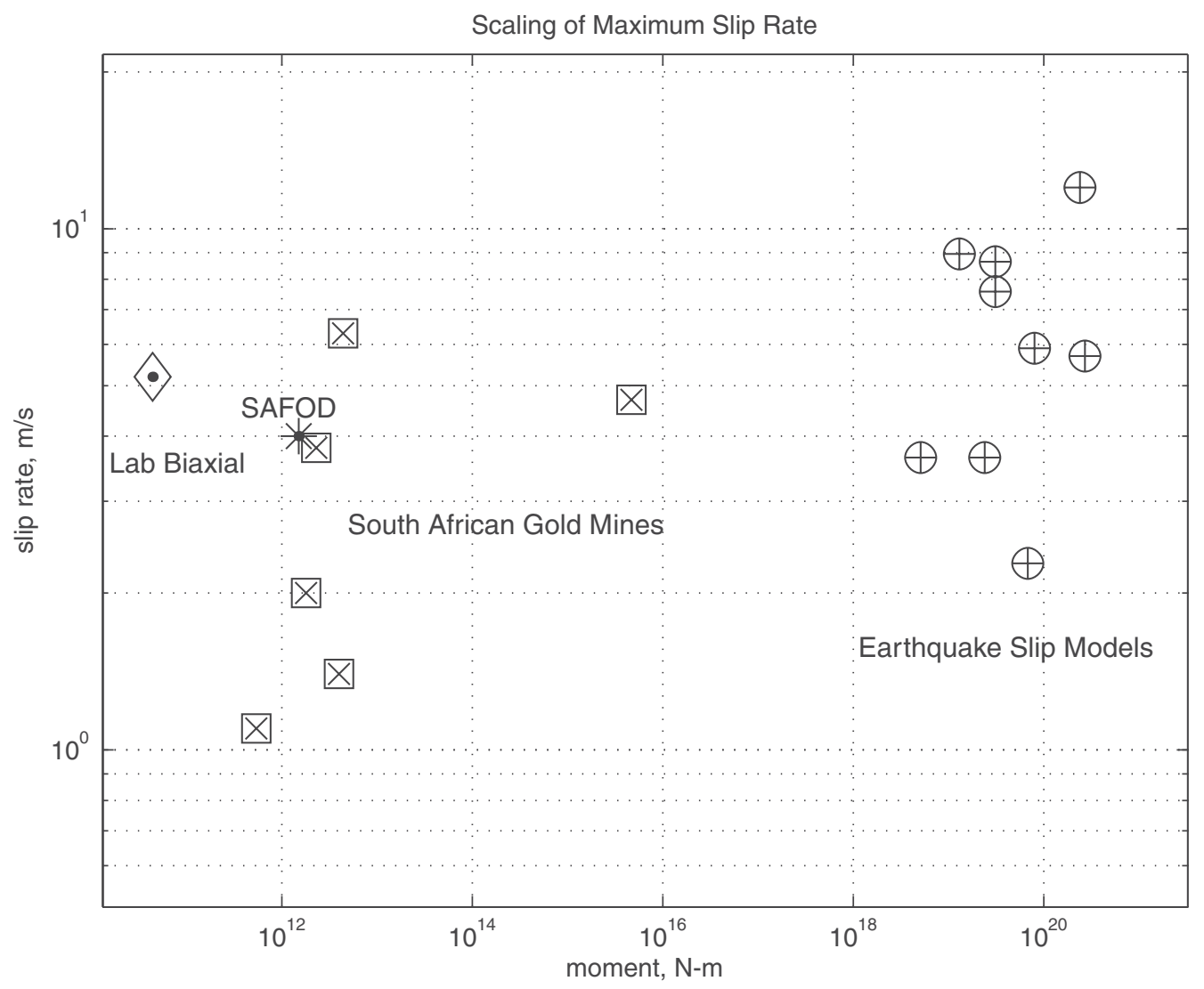

Figure 6. Maximum slip rates for adjusted laboratory event 9, the earthquakes listed in Table 3, and major tectonic earthquakes as functions of seismic moment. The rates for the major earthquakes were derived from slip models by McGarr and Fletcher (2007).

The other departure from the analysis of McGarr (1991) is to replace the median radiation factor of 0.57 (Spottiswoode and McGarr, 1975) with the more commonly used root mean square radiation factor (Aki and Richards, 1980, p. 120) $\left\langle R_{\theta \phi}\right\rangle=0.63$. Thus, on average,

$$
R \underline{v}=0.087 \beta D_{\max } .
$$

Equation (5) is not vastly different from its counterpart equation 22 in McGarr (1991), given previously, but the assumptions leading to it are more consistent with current practice.

Equation (3) allowed us to avoid having to estimate either $r$ or $T$ in this analysis, but it also introduced considerable model dependence and, thus, most of the uncertainty. Other source models would yield different versions of equation (5). Accordingly, it is important to consider independent evidence to find out whether equation (5) gives realistic results. To do this, we consider observations from this study and several previous ones of $R \underline{v}$ and $D_{\max }$ (Table 1).

As seen in Table 1, there are two earthquakes for which both $R \underline{v}$ and $D_{\max }$ have been measured, events 1040939 and, as already noted, 12/12/2004. For the first and larger one, $D_{\max }$ estimated using equation (5) is $0.23 \mathrm{~m}$, which is consistent with the maximum slip observed underground, $0.2 \mathrm{~m}$ (Brummer and Rorke, 1990).

For event 12/12/2004, our estimate of $R \underline{v}$ is based on peak ground velocity measured at five in-mine stations, all of which showed high signal/noise. The median estimate of $R \underline{v}, 4.98 \mathrm{~m}^{2} / \mathrm{sec}$, was from ground velocity corrected assuming $Q=200$ (Hemp and Goldbach, 1993) and recorded at in-mine station tau 19 , located $2.6 \mathrm{~km}$ from the hypocenter, which was close to where the corresponding fault slip of $25 \mathrm{~mm}$ was measured (Reches et al., 2006). For this median $R \underline{v}, D_{\max }$, estimated from equation (5), is $16 \mathrm{~mm}$, which is somewhat smaller than the maximum slip measured underground (Table 1).

In Figure 5 we have plotted all of the data listed in Table 1 as functions of $M_{0}$. Each measurement of $R \underline{v}$ was converted to its equivalent $D_{\max }$ using equation (5), with $\beta=$ $3600 \mathrm{~m} / \mathrm{sec}$ (McGarr, 1992b). As seen here, the $D_{\max }$ measured directly (diamonds) are quite consistent with those inferred using equation (5) (circles), and they all scale as $M_{0}^{1 / 3}$ (solid line in Fig. 5). The agreement seen in Figure 5 between the two types of data is evidence that equation (5) is a viable means of estimating $D_{\max }$ from $R \underline{v}$. 

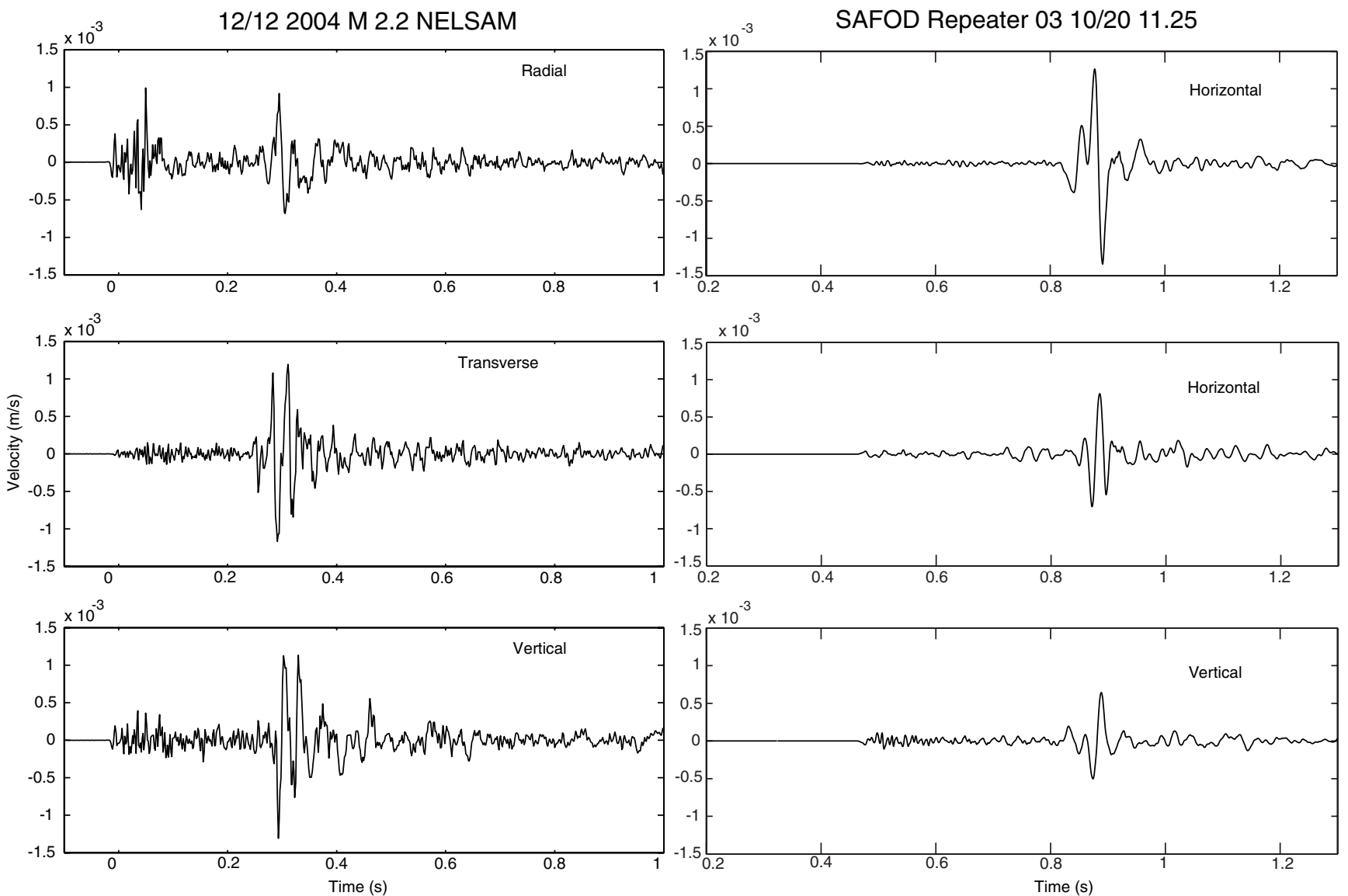

Figure 7. The left-hand column shows ground velocity for event 12/24/2004 recorded at in-mine station tau 19 at a sampling rate of 625 samples/sec, and the column on the right shows the same for event 0310201125 recorded in the SAFOD pilot hole at 2000 samples/ second. Tau 19 is located at almost the same location in map view as station T120 (Fig. 3), but its depth, 2.3 km, is much shallower. The velocity and time scales for all six seismograms are identical.

Table 1

Peak Velocity Parameters and Maximum Slips

\begin{tabular}{llcll}
\hline \multicolumn{1}{c}{ Event } & $M_{0}, \mathrm{~N} \mathrm{~m}^{*}$ & $R \underline{\underline{v}}, \mathrm{~m}^{2} / \mathrm{sec}$ & $D_{\max }, \mathrm{m}$ & \multicolumn{1}{c}{ Reference } \\
\hline Event 3 & $4.4 \times 10^{12}$ & $8.54^{\dagger}$ & & This study \\
Event 4 & $1.8 \times 10^{12}$ & $3.05^{\dagger}$ & & This study \\
Event 5 & $5.4 \times 10^{11}$ & $1.35^{\dagger}$ & & This study \\
Event 6 & $4.0 \times 10^{12}$ & $3.06^{\dagger}$ & & This study \\
0310201125 & $1.51 \times 10^{12}$ & $3.43^{\ddagger \dagger}$ & & Imanishi/Ellsworth (2006) \\
1040939 & $4.7 \times 10^{15}$ & 72.5 & 0.2 & McGarr (1991) \\
$12 / 12 / 2004$ & $2.3 \times 10^{12}$ & $4.98^{\ddagger \dagger}$ & 0.025 & Reches et al. (2006) \\
1989 Brand & $7.9 \times 10^{15}$ & & 0.37 & Dor et al. (2001) \\
1982 Welk & $1.8 \times 10^{16}$ & & 0.41 & Dor et al. (2001) \\
1992 Welk & $1.26 \times 10^{16}$ & & 0.15 & Dor et al. (2001) \\
1999 Welk & $5.0 \times 10^{16}$ & & 0.44 & Dor et al. (2001) \\
Wessel fault & $1.0 \times 10^{16}$ & & 0.5 & Brummer and Rorke (1990) \\
1986 2 Shaft & $1.26 \times 10^{16}$ & & 0.2 & Brummer and Rorke (1990) \\
\hline
\end{tabular}

Seismic moment tensors for events 3-6 and 12/12/2004 were determined by M. Boettcher et al. (unpublished manuscript, 2009). The deviatoric components of these solutions are listed here (see also McGarr, 1992a).

${ }^{\dagger}$ Ground velocities corrected for anelastic and scattering attenuation using $Q=200$.

${ }^{\dagger}$ From this study. 


\section{Maximum Slip Rate}

If equation (5) is an effective means of estimating $D_{\max }$ in the patch of the fault zone with the highest slip, can we go further and estimate the maximum slip-rate $\dot{D}_{\text {max }}$ in the same high-slip patch? To address this question, we propose a method of estimating $\dot{D}_{\max }$ by applying laboratory results to earthquakes for which $D_{\max }$ and $M_{0}$ have been estimated.

In recent reports (McGarr and Fletcher, 2003, 2007), we have indicated how to relate laboratory results from stick-slip friction experiments to corresponding parameters for earthquakes. Data from large-scale biaxial friction experiments from a study by Lockner and Okubo (1983) are especially well suited to our requirements here. Table 2 lists slips $D$ and normal stresses $\sigma_{n}$ from 15 experiments of that study. Because these experiments were run at a number of different normal stresses and as $\sigma_{n}$ is the main factor controlling the results of these stick-slip friction tests, we have adjusted all of the slips in Table 2 to take the different normal stresses into account. That is, we have multiplied all of the slips listed in the second column by the stress adjustment factor in the fourth column so as to simulate 15 experiments all run at the same normal stress of 3.0 MPa. As seen in Table 2, the median adjusted slip is from event 9 .

Accordingly, in the following analysis we consider event 9, with a slip of $93 \mu \mathrm{m}$ (Table 2) to be the representative laboratory earthquake for purposes of estimating maximum slip rates and loading stresses for mining-induced earthquakes. To determine the corresponding maximum slip-rate $\dot{D}_{\max }$ for event 9, we depart slightly from what was estimated by McGarr and Fletcher (2007) based on the slip-rate record shown in figure 4 of that report, a maximum slip rate of $0.1 \mathrm{~m} / \mathrm{sec}$. Because the slip-rate trace for event 9 exhibited a high level of noise, we decided to use a more stable procedure to estimate $\dot{D}_{\max }$, based on the constant rise time of $2 \mathrm{~ms}$ (determined by the stiffness and mass of the laboratory

Table 2

Laboratory Slips and Normal Stresses (Lockner and Okubo, 1983)

\begin{tabular}{rrccc}
\hline Event & $D, \mu \mathrm{m}$ & $\sigma_{n}, \mathrm{MPa}$ & $3.0 \mathrm{MPa} / \sigma_{n}$ & Adjusted $D, \mu \mathrm{m}$ \\
\hline 5 & 62 & 1.66 & 1.81 & 112 \\
6 & 70 & 1.66 & 1.81 & 127 \\
7 & 73 & 2.21 & 1.36 & 99 \\
8 & 84 & 2.21 & 1.36 & 114 \\
9 & 93 & 2.76 & 1.09 & 101 \\
10 & 97 & 2.76 & 1.09 & 106 \\
11 & 145 & 3.31 & 0.91 & 132 \\
12 & 128 & 3.31 & 0.91 & 116 \\
13 & 127 & 4.41 & 0.68 & 86 \\
14 & 142 & 4.41 & 0.68 & 97 \\
15 & 119 & 4.41 & 0.68 & 81 \\
16 & 134 & 4.41 & 0.68 & 91 \\
17 & 74 & 4.41 & 0.68 & 50 \\
18 & 105 & 4.41 & 0.68 & 71 \\
19 & 126 & 3.45 & 0.87 & 110 \\
\hline
\end{tabular}

testing system) for these laboratory stick-slip events (e.g., figure 3 of Lockner and Okubo, 1983). The revised procedure is to assume, as we did before in deriving equation (5), that the slip rate can be represented as an isosceles triangle whose base $T$, the rise time, is $2 \mathrm{msec}$. With this triangle representation of slip rate the maximum slip rate is given by

$$
\dot{D}_{\max }=\frac{2 D}{T}
$$

Thus, for event 9 , with $D=93 \times 10^{-6} \mathrm{~m}$, the revised slip rate is $0.093 \mathrm{~m} / \mathrm{sec}$, which is only slightly less than what McGarr and Fletcher (2007) estimated before $(0.1 \mathrm{~m} / \mathrm{sec})$ from the noisy trace of slip rate. This revised procedure has the important advantage, however, of allowing a maximum slip-rate estimate for any of the events for which we know the final slip, which is much easier to measure and more widely available than direct measurements of maximum slip rate. Thus, in the following analysis, we use event 9, which has a slip of $93 \mu \mathrm{m}$ and an estimated maximum slip rate of $0.093 \mathrm{~m} / \mathrm{sec}$, to infer the maximum slip rates of the earthquakes listed in Table 1 for which $R \underline{v}$ has been measured.

The first step in using event 9 to simulate an earthquake is to replace the laboratory fault surface $(2 \mathrm{~m}$ long by $0.4 \mathrm{~m}$ wide) with a buried circular shear crack whose radius, $10.4 \mathrm{~m}$, is chosen to match the laboratory stiffness, 3.3 MPa $/ \mathrm{mm}$ (Lockner and Okubo, 1983). That is, $\frac{7 \pi G}{16 r}=$ 3.3 MPa/mm (Walsh, 1971; McGarr and Fletcher, 2007). After applying this stiffness adjustment, the seismic moment for event 9 is $7.9 \times 10^{8} \mathrm{~N} \mathrm{~m} ; G=2.5 \times 10^{4} \mathrm{MPa}$ for the laboratory granite samples (Lockner and Okubo, 1983).

We can adjust event 9 so that it is located at any arbitrary location in Figure 5 by changing the slip or the radius or both. If we change only the slip but leave the radius unchanged then the new slip rate can be easily estimated using equation (6) because $T$ remains $2 \mathrm{msec}$. For example, we can adjust event 9 so that it is situated on the regression line (McGarr and Fletcher, 2003) in Figure 5 but retains the same rise time $T$ for the slip. This regression line, and lines parallel to it, represent scaling for which the loading stresses remain constant. For these lines, slip is related to seismic moment according to

$$
D_{\max }=C M_{0}^{1 / 3},
$$

where $C$ is a constant. For the regression line in Figure 5, $C=10^{-5.83}$ (McGarr and Fletcher, 2003), and so we solve $D_{\max }=10^{-5.83}\left(\pi r^{2} G D_{\max }\right)^{1 / 3}$ and find that $D_{\max }=$ $5.24 \mathrm{~mm}$. As $T$ is still $2 \mathrm{msec}(r=10.4 \mathrm{~m})$, the maximum slip rate of this adjusted version of lab event 9 is $5.2 \mathrm{~m} / \mathrm{sec}$ from equation (6). Because the regression line in Figure 5 is a line of constant stress drop, any point along this line has the same slip rate of $5.2 \mathrm{~m} / \mathrm{sec}$. This adjusted version of event 9 , which has a seismic moment of $4.45 \times 10^{10} \mathrm{~N} \mathrm{~m}$, is plotted in Figure 5 (diamond near lower left of plot). 
Because equation (7) can be fit to any point in Figure 5 by adjusting $C$, we can estimate the maximum slip rate for a given earthquake of seismic moment $M_{0}$ and maximum slip $D_{\max }$ by first determining $C$ and then solving for the adjusted laboratory slip $D$ using equation (7)

$$
D^{2 / 3}=C\left(\pi r^{2} G\right)^{1 / 3},
$$

where $r=10.4 \mathrm{~m}$ and $G=2.5 \times 10^{4} \mathrm{MPa}$. Then the maximum slip rate is estimated by substituting the result for $D$ into equation (6) with $T=2$ msec.

(Note that the rise time $T$ for slip on a small patch of a rupture surface is generally shorter than the duration of the earthquake as shown by slip models developed for major earthquakes [e.g., Wald and Heaton, 1994].)

Table 3 lists the results of applying (5)-(8) to the events listed in Table 1 for which $R \underline{v}$ has been measured. Seismic moments have been repeated from Table 1. As an example, consider event 3 for which $M_{0}=4.4 \times 10^{12} \mathrm{~N} \mathrm{~m}$ and $D_{\max }=27.3 \mathrm{~mm}$ from equation (5). Solving equation (7) using these values yields $C=1.67 \times 10^{-6}$. We then use equation (8) to find that $D=6.3 \times 10^{-3} \mathrm{~m}$ and from equation (6), $\dot{D}_{\max }=6.3 \mathrm{~m} / \mathrm{sec}$, for the adjusted lab earthquake and for event 3 , as listed in Table 3.

The maximum slip rates listed in Table 3 are plotted in Figure 6. Also plotted here are the maximum slip rates for the adjusted lab event and, at much larger moments, from slip models developed for major earthquakes (McGarr and Fletcher, 2007). We see in Figure 6 that all of the maximum slip rates fall in the range 1.1 to $12 \mathrm{~m} / \mathrm{sec}$ with no systematic dependence on seismic moment.

\section{SAFOD Earthquake 0310201125}

The mining-induced earthquakes analyzed here and some repeating earthquakes near the SAFOD site are similar in at least a few respects. For both, the hypocentral depths are near $3 \mathrm{~km}$ and many of the magnitudes are close to 2 . Accordingly, we decided to consider a well-studied earthquake of $M 2.1$ that occurred in 2003 and was recorded by the SAFOD pilot hole seismic array (Imanishi and Ellsworth, 2006). This earthquake, the largest reported by Imanishi and Ellsworth, is number 19 in their Table 1 and is designated 0310201125; this name is based on year,

Table 3

Maximum Slips and Slip Rates

\begin{tabular}{lccc}
\hline \multicolumn{1}{c}{ Event } & $M_{0}, \mathrm{~N} \mathrm{~m}$ & $D_{\max }(R \underline{v}), \mathrm{mm}$ & $\dot{D}_{\max }, \mathrm{m} / \mathrm{sec}$ \\
\hline Event 3 & $4.4 \times 10^{12}$ & 27.3 & 6.3 \\
Event 4 & $1.8 \times 10^{12}$ & 9.7 & 2.0 \\
Event 5 & $5.4 \times 10^{11}$ & 4.3 & 1.1 \\
Event 6 & $4.0 \times 10^{12}$ & 9.8 & 1.4 \\
$12 / 12 / 2004$ & $2.3 \times 10^{12}$ & 15.9 & 3.8 \\
1040939 & $4.7 \times 10^{15}$ & 231.5 & 4.7 \\
0310201125 & $1.51 \times 10^{12}$ & $14.1^{*}$ & 4.0 \\
\hline
\end{tabular}

"Estimated using $\beta=2800 \mathrm{~m} / \mathrm{sec}$ in equation (5). month, day, hour, and minute (yymmddhhmm, Greenwich Mean Time).

As seen in Table 1, the seismic moment and peak velocity parameter of event 0310201125 are similar to those of the four earthquakes in our broadband deployment, events 3 to 6 and also event 12/12/2004. Correspondingly, the maximum slip and maximum slip rate for 0310201125 are also much the same as for the mining-induced earthquakes, as seen in Table 3.

As further illustration of their similarities, we show records of ground velocity that were used in estimating $R \underline{v}$ for events 12/12/2004 and 0310201125 (Fig. 7). In the case of 0310201125, seismograms recorded at 2000 samples/sec from 15 levels in the SAFOD pilot hole showed good signal/noise and evidence that all three components were operational; the three components of ground velocity shown on the right-hand side of Figure 7 are from level 27 (depth $1.056 \mathrm{~km}$ ), the borehole site that yielded the median value of $R \underline{v}$ (Table 1). The hypocentral distance to that site is $2.2 \mathrm{~km}$. The velocities for event $12 / 12 / 2004$, recorded at $625 \mathrm{samples} / \mathrm{sec}$ at in-mine station tau 19 at a hypocentral distance of $2.6 \mathrm{~km}$, are shown on the left-hand side of Figure 7. For both earthquakes, the ground-motion data have been corrected for attenuation assuming $Q=200$ (Hemp and Goldbach, 1993; Imanishi et al., 2004). We see in Figure 7 that the records for both events are quite similar, especially with regard to peak amplitudes and pulse durations.

Indeed, our analysis suggests that the maximum slips and slip rates for all of the mining-induced earthquakes considered here and SAFOD event 0310201125 (Imanishi and Ellsworth, 2006) are not only similar but also adhere more generally to expectations for earthquakes in continental crustal settings. The maximum slips, observed directly or inferred from $R \underline{v}$ (Fig. 5), are consistent with a much broader set of maximum slips for earthquakes with magnitudes as high as 7.9 as reported by McGarr and Fletcher (2003), and their maximum slip rates (Fig. 6) are comparable to those inferred for major earthquakes (McGarr and Fletcher, 2007).

The similarities between the mining-induced earthquakes analyzed here and event 0310201125, including source depth, seismic moment, $R \underline{v}$, and inferred estimates of maximum slip and slip rate (Tables 1 and 3), are somewhat unexpected in view of their different settings. Whereas 0310201125 is thought to involve slip across a seismogenic asperity embedded in an actively-creeping part of the San Andreas fault zone, the mining-induced earthquakes occurred in an exceptionally stable tectonic setting. Among the contrasts between these earthquakes is the difference in pore pressure, approximately hydrostatic for 0310201125 (e.g., Hickman and Zoback, 2004) and close to zero for the mining events due to the water table drawdown associated with mining operations.

Finally, we note that our findings for event 0310201125 are not in accord with those from several studies using different approaches including that reported by Dreger et al. (2007), who determined a maximum slip of $103 \mathrm{~mm}$ for this 
event (event EVT1 in their table 1). The technique employed by Nadeau and Johnson (1998) on similar repeating earthquakes near SAFOD would have yielded a comparably high slip for event 0310201125, according to Dreger et al. (2007). We have no explanation for this first-order discrepancy (103 $\mathrm{mm}$ versus $14 \mathrm{~mm}$ ). More research is needed to answer the question of whether the small repeating earthquakes near SAFOD are ordinary or exotic.

\section{Concluding Remarks}

Our temporary deployment of IRIS/PASSCAL stations at depths ranging from 2 to $3.6 \mathrm{~km}$ within two of the deepest mines worldwide yielded such clean waveforms that we were inspired to try to estimate both the maximum slip and the maximum slip rate within the rupture zone of an earthquake. Our analysis of four earthquakes with magnitudes of about 2 revealed estimated maximum slips ranging from 4 to $27 \mathrm{~mm}$ that are consistent with underground observations of maximum slip reported in previous studies (Fig. 5).

To estimate maximum slip rates in the same high-slip patches of the rupture zone, we used the results of laboratory stick-slip friction experiments to determine rates ranging from 1.1 to $6.3 \mathrm{~m} / \mathrm{sec}$ (Table 3, Fig. 6). These peak rates fall within or slightly below the range found by analyzing slip models for major earthquakes, 2 to $12 \mathrm{~m} / \mathrm{sec}$ (McGarr and Fletcher, 2007). Thus, these results are consistent with the hypothesis that the physics of rupture does not vary with earthquake magnitude or moment, at least in continental crustal settings.

Finally, Figure 7 and the results listed in Tables 1 and 3 provide evidence that in terms of seismic radiation, an earthquake within a cluster of repeating earthquakes on the San Andreas fault, near the SAFOD site, appears to be similar, in many respects, to the mining-induced earthquakes of our study. As nearly as we can tell, the source processes of all these earthquakes seem to be largely the same (Tables 1 and 3 , Figs. 5 and 6) despite tectonic settings and pore pressures that are quite different.

\section{Data and Resources}

The IRIS/PASSCAL ground-motion data have been archived at the IRIS Data Management Center (DMC). Users of these data can register at http://www.iris.edu/data/ restricted_req.htm (last accessed December 2007). The borehole seismic data from the SAFOD pilot hole are archived at the Northern California Earthquake Data Center. Data for earthquakes near SAFOD can be accessed at http:// www.ncedc.org/2004parkfield.html (last accessed September 2008). The in-mine network data used here are proprietary.

\section{Acknowledgments}

We are grateful to IRIS/PASSCAL for the loan of the broadband systems that were key to the success of this project. Tony Ward, Sylvester
Morema, and Gilbert Morema, all with Seismogen; Lourens Scheepers, Frans Rheeder, and George Kgigori, all with Tautona Gold Mine; and Jonas Machake of the CSIR provided valuable support, especially underground, for this challenging project. We thank Nick Beeler, Bill Ellsworth, JeanRobert Grasso, and associate editor Michel Bouchon for helpful reviews of this manuscript.

\section{References}

Aki, K., and P. G. Richards (1980). Quantitative Seismology: Theory and Methods, Freeman, Cooper, San Francisco.

Brummer, R. K., and A. J. Rorke (1990). Case studies of large rockbursts in South African gold mines, in Rockbursts and Seismicity in Mines, C. Fairhurst (Editor), Balkema, Rotterdam, 323-329.

Brune, J. N. (1970). Tectonic stress and the spectra of seismic shear waves from earthquakes, J. Geophys. Res. 75, 4997-5009. (Correction [1971]. J. Geophys. Res. 76, 5002).

Churcher, J. M. (1990). The effect of propagation path on the measurement of seismic parameters, Rockbursts and Seismicity in Mines, C. Fairhurst (Editor), Balkema, Rotterdam, 205-209.

Das, S., and B. V. Kostrov (1983). Breaking of a single asperity: Rupture process and seismic radiation, J. Geophys. Res. 88, 4277-4288.

Dor, O., Z. Reches, and G. van Aswegen (2001). Fault zones associated with the Matjhabeng earthquake, 1999, South Africa, in Rockbursts and Seismicity in Mines, G. van Aswegen, R. J. Durrheim, and W. D. Ortlepp (Editors), South African Institute of Mining and Metallurgy, Johannesburg, 109-112.

Dreger, D., R. M. Nadeau, and A. Chung (2007). Repeating earthquake finite source models: Strong asperities revealed on the San Andreas fault, Geophys. Res. Lett. 34, L23302, doi 10.1029/2007GL031353.

Hanks, T. C., and R. K. McGuire (1981). The character of high frequency strong ground motion, Bull. Seismol. Soc. Am. 71, 2071-2095.

Hemp, D. A., and O. D. Goldbach (1993). The effect of backfill on ground motion in a stope during seismic events, Rockbursts and Seismicity in Mines, R. P. Young (Editor), Balkema, Rotterdam, 75-79.

Hickman, S., and M. D. Zoback (2004). Stress orientations and magnitudes in the SAFOD pilot hole, Geophys. Res. Lett. 31, L15S12, doi 10.1029/2004GL020043.

Imanishi, K., and W. L. Ellsworth (2006). Source scaling relationships of microearthquakes at Parkfield, CA, determined using the SAFOD pilot hole seismic array, Earthquakes: Radiated Energy and the Physics of Faulting, Geophys. Monograph Series 170, American Geophysical Union, R. Abercrombie, A. McGarr, H. Kanamori, and G. di Toro (Editors), doi 10.1029/170GM10, 81-90.

Imanishi, K., W. Ellsworth, and S. Prejean (2004). Earthquake source parameters determined by the SAFOD pilot hole seismic array, Geophys. Res. Lett. 31, L12S09, doi 10.1029/2004GL019420.

Lockner, D. A., and P. G. Okubo (1983). Measurements of frictional heating in granite, J. Geophys. Res. 88, 4313-4320.

McGarr, A. (1991). Observations constraining near-source ground motion estimated from locally recorded seismograms, J. Geophys. Res. 96, $16,495-16,508$

McGarr, A. (1992a). An implosive component in the seismic moment tensor of a mining-induced tremor, Geophys. Res. Lett. 19, 1579-1582.

McGarr, A. (1992b). Moment tensors of ten Witwatersrand tremors, Pure Appl. Geophys. 139, 781-800.

McGarr, A., and J. B. Fletcher (2003). Maximum slip in earthquake fault zones, apparent stress, and stick-slip friction, Bull. Seismol. Soc. Am. 93, 2355-2362.

McGarr, A., and J. B. Fletcher (2007). Near-fault peak ground velocity from earthquake and laboratory data, Bull. Seismol. Soc. Am. 97, 1502-1510.

Mendecki, A. J. (Editor) (1997). Seismic Monitoring in Mines, Chapman and Hall, London, 262 pp.

Nadeau, R. M., and L. R. Johnson (1998). Seismological studies at Parkfield VI: Moment release rates and estimates of source parameters for small repeating earthquakes, Bull. Seismol. Soc. Am. 88, 790-814. 
Ogasawara, H., and the Research Group for Semi-Controlled EarthquakeGeneration Experiments in South African Deep Gold Mines (2002). Review of semi-controlled earthquake-generation experiments in South African deep gold mines (1992-2001), in Seismogenic Process Monitoring, H. Ogasawara, T. Yanagidani, and M. Ando (Editors), Balkema, Tokyo, 119-150.

Reches, Z., and the Drilling Active Faults in South African Mines and the Natural Earthquake Laboratory in South African Mines Teams (2006) Building a natural earthquake laboratory at focal depth (DAFSAMNELSAM Project, South Africa), Scientific Drilling doi 10.2204/ iodp.sd.3.06.2006, 30-33.

Spottiswoode, S. M. (1993). Seismic attenuation in deep-level mines, in Rockbursts and Seismicity in Mines, R. P. Young (Editor), Balkema, Rotterdam, 409-414.

Spottiswoode, S. M., and A. McGarr (1975). Source parameters of tremors in a deep-level gold mine, Bull. Seismol. Soc. Am. 65, 93-112.

Wald, D. J., and T. H. Heaton (1994). Spatial and temporal distribution of slip for the 1992 Landers, California, earthquake, Bull. Seismol. Soc. Am. 84, 668-691.
Walsh, J. B. (1971). Stiffness in faulting and friction experiments, J. Geophys. Res. 76, 8597-8598

U.S. Geological Survey

MS 977345 Middlefield Rd.

Menlo Park, California 94025

mcgarr@usgs.gov

(A.M., M.B., J.B.F., R.S., M.J.S.J.)

Council for Scientific and Industrial Research Natural Resources and Environmental Unit

P.O. Box 91230

Auckland Park 2006, South Africa

(R.D., S.S., A.M.)

Manuscript received 24 November 2008 